\title{
«El jardín de la América meridional»... ciencia como deleite, información y el encanto de los jardines ingleses en un naturalista chileno en el Illuminismo italiano*
}

\author{
por \\ Francisco Orrego González ${ }^{1}$ \\ Universidad Andrés Bello, Chile
}

\begin{abstract}
El presente artículo quiere explorar en una de las diversas representaciones culturales que se elaboraron de la América meridional por uno de los tantos jesuitas expulsos en la Italia del Settecento como el naturalista e historiador chileno Juan Ignacio Molina (17401829). La expresión metafórica «El jardín de la América», permite adentrarse en las controversias culturales en torno a un objeto histórico que los historiadores culturales poco han abordado una escenografía natural particular como es el jardín. El trabajo sostiene, por medio del estudio de la historia natural de Chile escrita por Molina, junto a una memoria defendida por él mismo en la Accademia delle Scienze de Bolonia relativa a los jardines ingleses a inicios del siglo XIX, que el naturalista chileno fue un autor prerromántico gracias a las fuentes de información que utilizó para realizar estos trabajos en un escenario cultural particular como fue el Illuminismo italiano.
\end{abstract}

Palabras ClaVe: Juan Ignacio Molina; historia natural; jardines; fuentes de información; prerromanticismo.

Cómo Citar este artículo / Citation: Orrego González, Francisco, “«El jardín de la América meridional»... ciencia como deleite, información y el encanto de los jardines ingleses en un naturalista chileno en el Illuminismo italiano", Revista de Indias, LXXX/278 (Madrid, 2020): 131-162. https://doi.org/10.3989/revindias.2020.005.

* Este trabajo forma parte de los resultados centrales del proyecto Fondecyt de Iniciación $\mathrm{n}^{\circ} 11150490$. También este artículo pudo desarrollarse gracias al apoyo específico del proyecto HAR2016-75331-P financiado por la Agencia de Investigación Estatal de España (AIE) y del Fondo de Desarrollo Regional de la Unión Europea (FEDER, UE).

1 francisco.orrego@unab.cl, ORCID iD: https://orcid.org/0000-0001-7955-0598 


\section{INTRODUCCIÓN}

Para poder desarrollar el siguiente artículo sobre un naturalista tan conocido, como poco estudiado, como fue el exjesuita chileno Juan Ignacio Molina (17401829), quien integrara el grupo de esos casi 5000 jesuitas exiliados de los territorios de la monarquía hispana por real decreto de 27 de marzo de 1767 emitido por Carlos III (1716-1788), lo primero que se debe realizar es un riguroso acto de contrición historiográfica. La figura de este naturalista y religioso chileno, proveniente del llamado 'Flandes Indiano', es la evidencia de cómo las tradiciones historiográficas nacionales pueden llegar a distorsionar casi por completo el pasado y repetir sus tópicos una y otra vez ${ }^{2}$. Con ello, no queremos decir que el trabajo y la figura que la historiografía sobre el abate Molina, como se le conoció luego de la disolución canónica de la Compañía de Jesús en agosto de 1773 por la breve papal Dominus ac Redemptor dictada por Clemente XIV, sea expresión de un informe y vano pasado.

Sin embargo, bien es cierto que la realidad histórica viene a complejizarse cuando incluimos nuevos elementos históricos. En otras investigaciones sobre el trabajo y la práctica científica del abate Molina ${ }^{3}$, hemos comenzado a estudiar dicha obra desde una perspectiva global aproximándonos al naturalista chileno como una figura que encarna una serie de fronteras e intersticios culturales que han permitido corregir 'juicios' históricos exageradamente groseros. Una obra global, pues es pensada por un jesuita chileno, del Finis Terrae, pero escrita en una ciudad docta como Bolonia, y no en latín que continuaba siendo el lenguaje oficial de la ciencia, sino en perfecto italiano toscano. Sin duda, una obra que vivió, padeció y asimiló distancias, se movió y traspasó fronteras ${ }^{4}$. Por ejemplo, este tipo de prejuicios ha llevado a historiadores nacionalistas y de la propia Compañía de Jesús, incluso de la propia Universidad de Bolonia ${ }^{5}$, a otorgarle el estatus de «padre del evolucionismo biológico chileno» reclamando su paternidad sobre el trabajo científico de

2 La bibliografía molineana es sumamente ingente, aquí solo hacemos referencia a los ejemplos más representativos de esta situación historiográfica. Briones, 1968. Salinas, 1998. Hanisch, 1999. Rojas Mix, 2001. Saldivia, 2004.

3 Por ejemplo, Orrego, 2011, 2015 y 2017.

4 En esto seguimos los planteamientos de Ottmar Ette que considera que «los espacios políticos, culturales, económicos, sociales y también los literarios que nos circundan, desde la segunda mitad del siglo XVIII, se han modificado de una manera cada vez más veloz», una nueva cartografía de lo cultural, que trae como consecuencia un empequeñecimiento del espacio y alimentando la «transmisión mundial» Ette, 2008: 13-18.

5 El documento señala lo siguiente: «En marzo de 1968, en solemne acto público, la Universidad de Bolonia y la Academia de Ciencias del Instituto de Bolonia, le entregó a Juan 
naturalistas de la talla de Alexander von Humboldt (1769-1859)6 e incluso del propio Charles Darwin (1809-1882) ${ }^{7}$. Casos como estos no deben extrañarnos. Siempre las tradiciones historiográficas, interesadas como lo son, crean y reclaman la emergencia de sus polímatas sobre otros. Nada más ha faltado decir, con entusiasta patrioterismo nacional, que el abate Molina fue un excepcional, adelantado y temerario polímota de su tiempo, incluso más prometedor que Herbert Spencer (1820-1903), famosísimo e influyente intelectual europeo del siglo XIX, a quien también sus aduladores han querido posicionar como un precursor de las ideas evolucionistas antes que Darwin por la publicación de su obra «Progress: its Law and Cause» publicado en 1857 en The Westminster Review ${ }^{8}$.

Este artículo forma parte de un proyecto de investigación de mayor alcance historiográfico que tiene como objetivo estudiar la obra, la práctica, la actuación y las representaciones científicas de Juan Ignacio Molina en el tránsito del siglo XVIII al XIX, en el escenario general del espacio atlántico y en el marco específico de su trabajo científico en la Accademia delle Scienze del Instituto de Bolonia titulado «Juan Ignacio Molina y la 'Italia antártica'. Imperio, historia natural y los problemas en la producción de saberes científicos en el mundo atlántico (s. XVIII-XIX)». En consecuencia, el artículo tiene como propósito central generar nuevos y renovados marcos interpretativos del trabajo del exjesuita chileno y parte de la articulación transnacional de su trabajo como naturalista y como historiador. Es decir, para poder desarrollar este artículo, no podemos partir de otro planteamiento que no sea aproximarnos a la historia natural de Chile escrita por Molina como parte de una historia global, donde la historia natural del Reino de Chile en este período pasa a ser parte de la historia de la monarquía ibérica y su proyección global, y viceversa.

\footnotetext{
Ignacio Molina, insigne naturalista, el título de 'Precursor del evolucionismo biológico moderno'», Archivo Central Andrés Bello (ACAB), Fondo Rodolfo Jaramillo, Carpeta VII, s/p.

${ }^{6}$ El historiador chileno Walter Hanisch, jesuita, defendió el planteamiento que el método utilizado por Alexander von Humboldt fue desarrollado antes por el abate Molina: «lo usó con posterioridad a Molina, por lo cual el autor chileno viene a ser un antecedente de la obra del sabio investigador alemán», Hanisch, 1976: 27.

7 El autor chileno Januario Espinosa del Campo (1879-1946) ha sido uno de los autores que más defendió la hipotética paternidad de Molina sobre Darwin. Espinosa, 1946 y Jaramillo, 1965. Sobre la discusión histórica del título de "Precursores del evolucionismo moderno" véase Orrego, 2018.

8 Spencer, 1857. Sobre la importancia de la obra de Spencer puede verse el libro de Francis, 2008.
} 
UN SAGGIO DE 'RAÍCES’ IBÉRICAS

El Saggio sulla Storia Naturale del Cile fue publicado por primera vez en italiano en 1782 y luego en 1810 en Bolonia, es una obra que está dentro de la tradición cultural de historias naturales escritas por los jesuitas sobre los territorios americanos fundamentalmente desde 1775 en adelante 9 . Molina recurrió en su Saggio sobre Chile al sistema de clasificación taxonómica desarrollado por el naturalista sueco Carlos Linneo (1707-1778) en su obra Systema Naturae publicado por primera vez en Leiden en $1735^{10}$. para organizar su contenido y así proponer una clasificación actualizada y corregida de las especies chilenas que hasta ese momento se conocían y, especialmente, incluir las nuevas especies que los geógrafos y viajeros ilustrados habían descubierto tras sus viajes de circunnavegación global en el siglo XVIII ${ }^{11}$.

Figura 1. Juan Ignacio Molina, SagGio sulla Storia Naturale del Chili, in Bologna, Nella Stamperia di S. Tomasso D’ Aquino, 1782

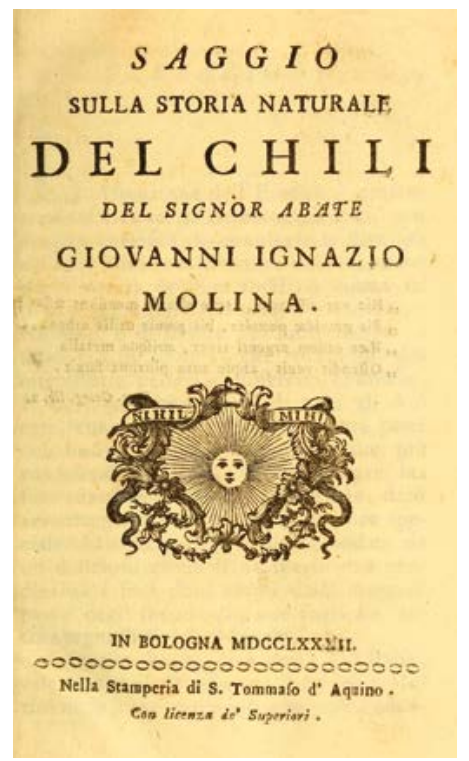

Fuente: Internet Archive (archive.org).

\footnotetext{
9 Cfr. Millones Figueroa y Ledezma, 2005. Rojas Mix, 2001.

10 Mollano, 2008.

11 Un muy buen ejemplo de este tipo de trabajos es el estudio de Pimentel, 2003. Valverde, 2012. Safier, 2016.
} 
Fue una obra de historia natural que permitió a los naturalistas europeos tener acceso al conocimiento de especies animales, plantas, fósiles, minerales y las características de una geografía como la del Reino de Chile que, a pesar de la intensa circulación de datos e información sobre las diversas regiones del globo hacia fines del s. XVIII, seguía siendo una parte del mundo en gran parte desconocida. La analogía acuñada casi un siglo antes por el misionero jesuita y cronista español Diego de Rosales (1601-1677), en su obra titulada Historia general de Chile. El Flandes Indiano, escrita en 1674, cargada de elementos narrativos propios de la tradición literaria hispana del siglo XVII ${ }^{12}$, parecía seguir siendo adecuada para describir un territorio imperial meridional muy particular del que se estimaba «no tener noticias suficientes» ${ }^{13}$.

Por esta razón, fue una historia que despertó rápidamente el interés de las autoridades hispanas, ¿interés genuinamente intelectual y/o cultural de parte de las autoridades ibéricas?, ¿o también representó un astuto, sutil y fascinante provecho de orden político? La respuesta monárquica fue múltiple y variada, pero a la vez sobria y severa. Fundamentalmente su interés en un texto que narraba la historia natural de un territorio aún poco conocido se encuentra en su contenido. Pero no cualquier contenido. Si se nos permite la calificación, era un contenido ético e imperial con extraordinarias correspondencias globales. Lo anterior, tanto por las fuentes de información que utiliza, especialmente extraídas de viajeros, como por el discurso político y cultural acorde a los intereses de la monarquía hispana ${ }^{14}$.

12 El término 'Flandes Indiano' fue acuñado por Diego de Rosales, jesuita de origen español, en su crónica escrita a fines del siglo XVII, en 1674 titulada expresivamente como Historia General del Reino de Chile. Flandes Indiano. Esta crónica, sorpresivamente solo se conoció a fines del siglo XIX cuando el político y escritor chileno, Benjamín Vicuña Mackenna, la imprimió entre 1877 y 1878 . Últimamente se ha intentado rescatar la importancia de este autor tanto desde la perspectiva histórica como literaria. Puede verse, a modo de ejemplo, para el caso de la historia está Gaune, 2017 y para el caso de la literatura el buen trabajo de Manuel Contreras, 2017.

${ }_{13}$ Molina escribía lo siguiente, a pesar de que en el siglo XVII, jesuitas españoles destacados como Alonso de Ovalle y el propio Diego de Rosales habían escrito sendas relaciones sobre el Reino de Chile, Molina a fines del siglo XVIII seguía insistiendo en el siguiente argumento relativo al tipo y cantidad de información sobre Chile: «Es cierto que los viajeros instruidos que han aportado en diferentes tiempos á sus playas, no han dexado de hablar de aquel Reyno; pero sus noticias son demasiado sucintas para que se pueda formar por ellas una justa idea de Chile», Molina, 1788: V-VI.

14 A pesar de que la historiografía especializada ha denominado tradicionalmente la 'expulsión de los jesuitas' al proceso que, en 1767, impuso el destierro por la fuerza a miles de religiosos pertenecientes a esta orden de los territorios dominados por la monarquía hispana, lo cierto es que dicha 'expulsión' nunca generó un rompimiento en la relación entre la mo- 
Ello deja en evidencia la importancia política y cultural que la monarquía hispana le otorgó al conocimiento de la historia natural. Desde los inicios de la modernidad y la globalización en el s. XVI, el conocimiento del territorio, las potencialidades de la historia natural americana y su relación con factores políticos, económicos, materiales y religiosos permitieron a los europeos soñar con el control del mundo ${ }^{15}$. Por tanto, el territorio y la historia natural americana fueron importantes elementos en la configuración del imaginario imperial hispano. Esta condición provocó que el conocimiento científico de este período fuese resultado de dinámicos flujos y circulaciones de naturalistas, modelos científicos y objetos relativos a la historia y la historia natural americana y europea en el espacio atlántico.

De tal forma, la originalidad del Saggio está en reconstruir y analizar una parte de la historia de Chile que los europeos poco, o nada, conocían junto

narquía y los hijos de la Compañía. Incluso, luego de su disolución en 1773. Todo lo contrario, la monarquía hispana mantuvo, por interés propio, una instrumental y tensa relación con estos religiosos en los diversos territorios italianos en los que se les permitió asentarse. Primero, a través de una fuerte restricción sobre los grados de asociación, es decir, podían vivir en un número muy reducido dado que la idea era mantenerlos separados. Y, en segundo lugar, dándoles una precaria pensión para la subsistencia de cada religioso. Este último elemento obligó a muchos integrantes de la Compañía a buscar diversas formas de financiamiento, entre los que estuvo la educación, pero otros aprovecharon sus habilidades intelectuales para escribir historias antiguas, naturales y civiles sobre sus territorios de origen. En un escenario cultural crítico para la monarquía hispana durante la segunda mitad del siglo XVIII, bien sabidas son las duras acusaciones realizadas por autores de otras tradiciones ilustradas de Europa, como las hechas por autores como De Paw, Robertson y Raynal, a la empresa colonial ibérica, la monarquía hispana encontró en los jesuitas extraordinarios agentes de defensa frente a estas duras imputaciones cuyo incentivo fue pagar pensiones extras a quienes escribieran a favor del honor nacional atacado por el resto de monarquías europeas. Claramente se convirtió en una relación funcional que benefició tanto a la monarquía hispana, necesitada de crear un nuevo discurso político y cultural sobre su pasado colonial, como a los religiosos exiliados que vivían en una pésima situación económica. Investigando en el fondo Santa Sede del Archivo General del Ministerio de Asuntos Exteriores de España uno puede encontrarse con varias cartas y memoriales que reflejan esta 'relación calculada' por señalarlo de alguna forma. Por ejemplo, en caso del naturalista chileno, en carta de Antonio Porlier dirigida al Nicolás de Azara fechada en San Lorenzo el 9 de octubre de 1788: «Habiendo hecho presente al Rey la instancia del Abate dn. Juan Ygnacio Molina qe. Me dirijió V.S. en su carta de 3 de septiembre ultimo sobre qe. se le concediese doble Pension en consideración al trabajo que há puesto en la Historia de Chile que há publicado en Ytaliano, me há mandado S.M. recordar esta instancia luego qe. salga ã luz el tomo segundo de la traducción Castellana qe. debe imprimirse en Madrid ã fin de qe. se recompense el merito del autor. Lo qe. pa. Noticia y satisfaccion de este, participo ã V.S. cuya vida qe Dios ms. as. Antonio Porlier», Archivo General, Ministerio Asuntos Exteriores (Madrid), Santa Sede, § 360, documento 15.

15 Nieto Olarte, 2013: 1-15. 
con la importancia que un exjesuita, como el abate Molina, le dio a esta disciplina cuyo propósito fue, por una parte, recomponer y, por la otra, describir su representación de la historia natural del Finis Terrae imperial. Para ello, el naturalista chileno recurrió a diversas creaciones humanas sobre la naturaleza ¿Qué tipo de creación humana podía resultar de tanta utilidad científica como que fuese capaz de despertar tanta admiración estética para llenar el gusto exigente de los versados naturalistas europeos de fines del siglo XVIII? Un espacio podía llegar a complacer, incluso provocar amplio deleite, en el gusto de las exigencias estilísticas de los miembros de la llamada República de las Letras: el jardín. Y Molina no dudó en recurrir a una potente y elogiosa analogía, una más, para describir ese Finis Terrae del siglo XVI o ese 'Flandes Indiano' del siglo XVII que era el Reino de Chile, pero esta vez bajo los criterios culturales del Illuminismo italiano: «El Jardín de la América». Que metáfora más reivindicativamente poderosa y bella que la de 'jardín' para una cultura científica de fines del siglo XVIII que ya podía verse empapada de corrientes prerrománticas.

A fin de cuentas, para un saggiatore como Molina, a pesar de su esfuerzo por desarrollar una retórica objetivista ${ }^{16}$, dada la importancia que le daba a la teología natural, la naturaleza era algo mucho más que una evidencia de leyes y resultado de una taxonomía. La naturaleza era una expresión del entusiasmo y efusión de la obra de Dios. En otras palabras, la naturaleza era capaz de despertar el enardecimiento del espíritu humano llevándolo a estados de contemplación propios de una experiencia tanto estética como mística. El rol de los jardines en el siglo XVIII transitó silenciosa y sutilmente, en el caso del abate Molina, desde las raíces ilustradas ibéricas a los riscos y cúspides propias de quien comienza a experimentar la imaginación romántica. Por ello, para una buena comprensión del planteamiento de este artículo, es fundamental aproximarse al fenómeno de la ciencia y su morfología escritural ${ }^{17}$, como hechos y actividades social e históricamente situados y que se encuentran afectados por los diversos intereses de las instituciones políticas, el ejercicio del poder y las manifestaciones y representaciones culturales de cada período $^{18}$. El trabajo científico de Juan Ignacio Molina está compuesto por diversas aristas que deben comenzar a estudiarse bajo estos nuevos enfoques históricos. Algunos de esos aspectos a estudiar son los 'espacios naturales' y las 'tradiciones intelectuales' por las que se interesó el exjesuita chileno y que queda-

16 La comprensión de Juan Ignacio Molina como un saggiatore moderno, puede verse en nuestro reciente trabajo, Orrego 2017.

17 Cfr. Locke, 1997: 29-31.

18 Shapin, 2000: 21 y 27. 
ron reflejados en sus obras sobre historia natural. El abate Molina fue un naturalista, pero también un ilustrado que se nutrió y formó parte activa, como hemos dicho, de esa 'comunidad invisible' denominada República de las Letras participando no solo de las controversias intelectuales que se generaron al interior de ella, sino también de la sensibilidad y el gusto que fue capaz de crear. El naturalista chileno formó parte de esa generación de autores que transitaron, a veces silenciosamente y en tensión con su propia formación ilustrada, hacia formas más sensibles de comprensión y explicación de las verdades de la naturaleza.

\section{EXPERIENCIA PERSONAL, LETRAS E 'INFLUENCIA' FRANCESA}

El interés de Molina por los jardines no deja de confrontarnos con las preguntas históricas. Preguntas que funcionan como hebras que tiramos y nos van develando paso a paso, hecho a hecho, en este caso, las rugosas caras del pasado de las concepciones científicas del naturalista chileno. En efecto, podríamos realizarnos el siguiente cuestionamiento ¿son los intereses y preocupaciones intelectuales del exjesuita chileno pura expresión del experimentalismo illuminista? A nuestro juicio, a la luz de las evidencias históricas, la respuesta es inequívoca: no. Los intereses, y la forma de entender y practicar la ciencia, por parte del exjesuita chileno dependen estrechamente de acontecimientos biográficos que deben ser incorporados en el complejo procesos de autoconstrucción de una identidad científica como señalábamos anteriormente. La ciencia para Molina no fue pura observación, era expresión de una sensibilidad. El desarrollo del trabajo y sensibilidad científica del naturalista chileno estuvo estrechamente ligada a un precoz y perceptivo interés literario. El exjesuita fue, quizás, el mayor exponente de creaciones literarias neolatinas chilenas antes de ser exiliado a tierras italianas ${ }^{19}$. Con apenas 21 años, y cursando los estudios de humanidades en la Compañía de Jesús en Chile, escribió alrededor de 1761 un conjunto de poemas reunidos bajo el nombre de Elejías Latinas en las que narra, entre otras cosas, su experiencia médica luego de haber contraído una enfermedad con extraordinaria fatalidad como la viruela. Un relato sobre una experiencia personal, pero que también debe ser visto como un ejercicio intelectual de retórica y descripción científica. Así queda expresado desde un inicio en el texto cuando señala: «Una prodigiosa enfermedad, salida de las cavernas de la Estigia, me invadió el cuerpo sin

19 Véase Brañes, 2017: 402-404. 
tener compasión conmigo. Primero la cabeza, luego el resto de los miembros, advierten los síntomas del mal que se avecina» ${ }^{20}$.

Y posteriormente, cuando culmina la 'fase toxémica' de la enfermedad, su lamento al encontrarse en las puertas de la muerte, casi falto de esperanza, en un agudo estado febril que describe en la primera Elegía del Libro II, titulada La Fiebre, recurre nuevamente a fórmulas literarias clásicas que le permitan expresar, con delicada y sensible narración, su percepción de la enfermedad, pero recurriendo a los elementos que configuran la naturaleza:

¡Al fin la noche se fue! Cansada de estar, dio a la luz su lugar. Nació en la tierra el día, ignoro como apareció: si nuboso o de brillante fulgor. El número de horas, no el brillo del cielo, me anuncian su arribo. Noche y día soporto el humear de la vela, que con luz mortecina anticipa mi funeral, mientras crece la fiebre sin fin y aumenta el malvado calor. Su padre es el fuego, su madre Flagetón ${ }^{21}$, la llama, máximo castigo entre los tenarios ${ }^{22}$ del lago subterráneo ${ }^{23}$. Hórrido monstruo, todo fuego, ardor completo, entero impía angustia, todo dolor del alma. Se introduce por el cuerpo entero, para dentro hacerme la guerra, mal salvaje ${ }^{24}$.

Estigia, en la mitología griega y romana, fue una ninfa oceánide que personificaba el río del inframundo. Su origen está en un territorio también cargado de nociones y leyendas como la Arcadia. Allí, Estigia tutelaba desde una fuente o un estanque la comunicación con el Hades. Sin introducirnos en este tema, el uso de figuras literarias procedentes de la antigüedad, como la fuente, el estanque o el jardín, tal como señala el título de este trabajo y en el que nos detendremos más adelante, usadas por Juan Ignacio Molina, son un recurso frecuente que aparecerá en los posteriores escritos sobre historia natural del exjesuita chileno a inicios del siglo XIX. Una fórmula literaria por la que el naturalista optó tempranamente. Por alguna particular razón, para el abate Molina, el territorio chileno no posee lagos sino «fuentes cristalinas perennes $\rangle^{25}$. Y por alguna otra causa, los historiadores no hemos reparado en este tipo de sutilezas para observar la historia natural del período moderno concentrándonos en otros elementos que ponen de relieve su interés científico

20 Molina, 1761: 67. La cursiva es nuestra. También queremos agradecer al Dr. Jorge Cáceres del Departamento en Humanidades de la Universidad Andrés Bello por facilitarnos la versión de las Elegías de Juan Ignacio Molina editadas por Rodolfo Jaramillo, cuyo texto actualmente es muy difícil de conseguir.

21 Río de fuego infernal.

22 Habitantes del Ténaro (infierno).

23 En este párrafo, el abate Molina se refiere a la laguna Estigia en el infierno.

24 Molina, 1761: 79.

25 Molina, 1788: 43. 
y político ¿Y qué pasa con su estilo? ¿Acaso la historia natural no es también una forma de escritura? ¿Acaso el género de la historia natural está fuera de las controversias sobre el gusto y el estilo de la cultura en el siglo XVIII?

La referencia clásica a la que hace alusión el naturalista chileno en este poema de juventud, mezcla la variable personal o biográfica con el gozo que le genera una conducta científica moderna, como la observación y la descripción, pero bajo una dimensión tanto estética como ética. Esta última condición no puede dejarse pasar sin una mirada histórica y crítica, más aún en un religioso jesuita, con una educación privilegiada en autores clásicos que se preocuparon de temas de historia natural como geografía ${ }^{26}$, inserto en la globalidad de la modernidad europea que transita entre el siglo XVIII y XIX. Para algunos autores, por ejemplo, la práctica de la jardinería podría orientar la búsqueda del bien común y mejorar la convivencia social. En ese sentido, sería una escuela de «rectitud moral y un escenario para la buena vida y la salud privada y pública» ${ }^{27}$.

Por ello, la presencia de la retórica objetivista y descriptiva quedará claramente expresada en su primera gran obra, que fue la que le dio fama de naturalista en Europa, el Saggio sulla storia naturale del Chili al que hacíamos referencia anteriormente con la que práctico cierto estilo de crítica narrativa e histórica ${ }^{28}$. Referencias como «yo tengo visto», «he visto», «algunas personas que vieron», «algunas personas que observando», «mis propias observaciones», «cuyo conocimiento deben a su propia experiencia», «vestigios», «esta descripción», «muy verosímil», «deducir un indicio análogo que no fuese falaz», y quizás la más contundente y conclusiva: «Yo he visto, y he observado con suma atención quantas cosas escribo» ${ }^{29}$, son parte del nutrido arsenal de fórmulas retóricas que evidencian la importancia que el abate Molina dio a la objetividad. Dicha retórica muestra la magnitud que el naturalista chileno dio, en clave filosófica, al 'yo', es decir, a la experiencia personal y, en consecuencia, el hom-

${ }^{26}$ En la lectura detenida del Saggio sulla storia naturale del Chili es latamente reconocible, aún a fines del siglo XVIII, las obras de autores clásicos como la Historia Natural de Plinio o la Geografía de Estrabón. Incluso, en el caso de Molina, la influencia de Plinio continuó en el siglo XIX cuando se dedicó a escribir sus memorias de historia natural que fueron publicadas en Bolonia en dos volúmenes entre 1821 y 1822 como Memorie di Storia Naturale en la Tipografia Marsigli. En su memoria dedicada a los jardines, y describiendo las voluptuosas «delicias campestres» con las que contaban los romanos, el naturalista chileno señala lo siguiente de los romanos: "quisieron tener algunas similares en la ciudad: "Jam quidam", dice el naturalista Plinio, "hortorum nomine in ipsa Urbe agros, villas que possident"», Molina, 2003: 78.

27 Beruete, 2016: 20.

28 Cfr. Hachim Lara, 2017: 329.

29 Molina, 1788: XV. 
bre debía aspirar a establecer una sensible relación con la naturaleza y con sus espacios como los que nombrábamos anteriormente. Son escenografías naturales - la fuente, el estanque o el jardín - que, en la visión de un ilustrado como Molina, están para entregar un mensaje pedagógico y moral. Allí demuestra como la raíz clásica es importante para él en este tema explicando su conflicto con algunas tradiciones culturales en un complejo tránsito de cambio de identidad científica. En el mundo antiguo estas 'escenografías naturales' nunca estuvieron separadas de los procesos de formación intelectual. Así lo evidencian las nociones e ideales del Akademos platónicos y la del Liceo aristotélico que se encarnaban en sendos parques por solo centrarnos en dos grandes autores ${ }^{30}$.

En este aspecto, y retomando el título original de su historia natural sobre Chile, Juan Ignacio Molina no es solo un científico religioso con preocupaciones pedagógicas ${ }^{31}$, es decir, morales, sino un convencido saggiatore. Este tipo de afirmaciones no debiesen sorprender en un 'naturalista ilustrado' como el exjesuita chileno. Lo que sí sorprende, sin dejar de lado la presencia de retórica objetivista moderna, son las resueltas afirmaciones con las que el abate inicia su historia natural de Chile. Nada más avanzadas unas líneas en el Saggio sulla storia naturale, 'describe y califica' el Reino de Chile en los siguientes términos: «Este país es, por decirlo asi, la Italia, ó mas bien el jardín de la América meridional, en donde brilla con la misma perfeccion y abundancia que en Europa todo quanto puede apetecer» ${ }^{32}$.

La definición anterior inspira los planteamientos y el análisis propuesto en este artículo y, a nuestro entender, sustenta la necesidad de estudiar históricamente la obra científica de este exjesuita incorporando variantes culturales.

30 Beruete, 2016: 26.

31 La dificultad económica a la que se enfrentaron los jesuitas, sumado al agrio recibimiento por sus cofrades italianos representados por la decisión del General italiano de la Compañía en ese período, Lorenzo Ricci, que prohibió a las provincias italianas acoger en sus estructuras a los expulsos españoles influyeron en los diversos mecanismos de integración que los exiliados pusieron en práctica a su llegada a los Estados Pontificios. Una de las estrategias más usadas por ellos fue posicionarse en los espacios educativos. Muchos de los jesuitas se aplicaron especialmente como preceptores privados de los jóvenes hijos de las elites italianas en la región de la Emilia-Romagna para hacer frente a los padecimientos económicos. Juan Ignacio Molina no actuó de manera diferente, y lo primero que hizo debido a las dificultades económicas fue relacionarse con la sociedad bolognesa y practicar la educación privada dedicándose especialmente a la enseñanza de la geografía, la historia, historia natural y el francés y latín. Llegó a montar una escuela privada en su casa de calle Belmeloro 3102, cuyo permiso era entregado tras rendir algunas pruebas de moralidad e idoneidad de las materias enseñadas. Para este tema, véase, por ejemplo, Guasti, 2009: 257-278 y también el ya clásico, pero aún insustituible trabajo, de Batllori, 1966.

32 Molina, 1788: IV. La cursiva es nuestra. 
En la cita anterior, la sensibilidad de Molina queda 'literariamente' expresada, casi como una declaración geográfica de principios estéticos sobre la naturaleza. La descripción que el naturalista chileno realiza en esta frase es de tanta relevancia histórica, que su estudio riguroso ayudaría a cambiar, sin duda, los puntos de arranque en el análisis de los planteamientos, prácticas científicas y marco cultural en el que se desarrolló el proceso de autoconstrucción de una identidad científica como naturalista. El proceso intelectual anterior comenzará con claridad en 1774 , año en que llega a la ilustrada ciudad de Bolonia, y en la que permanecerá definitivamente hasta su fallecimiento a los 89 años en 1829 tras un intento de volver a Chile en los primeros años del siglo XIX cuando el retorno es autorizado por el rey, pero que finalmente no termina llevándose a cabo por su avanzada edad y por la disuasión frente a esta idea realizada por su amigo Conde del Maule, Nicolás de la Cruz y Bahamonde, militar y comerciante chileno radicado en Cádiz ${ }^{33}$.

El concepto clave de la declaración de Molina expuesta anteriormente es uno: el de jardín. La utilización de una analogía como «el jardín de la América meridional» representa, por una parte, el extraordinario conocimiento de la cultura clásica del naturalista chileno y, por otra, las contorsiones retóricas que éste realizó para alcanzar un propósito muy conocido para los estudiosos de las controversias científicas del siglo XVIII: responder a los filósofos ilustrados de Europa del norte. Estos ataques estuvieron encarnados especialmente en los trabajos del escocés Williams Robertson (1721-1793), el abate francés Guillaume-Thomas Raynal (1713-1796) y, especialmente, el alemán Cornelius de Paw (1739-1799), quienes, para el abate chileno como para otros jesuitas exiliados en Italia como el quiteño Juan de Velasco y el mexicano Francisco Xavier Clavigero, calumniaron y denigraron el territorio, las producciones naturales y a los habitantes de las Américas ${ }^{34}$. La llamada 'disputa

33 Nicolás de la Cruz y Bahamonde (1760-1828), fue conocido como Conde del Maule al haber nacido en la recientemente fundada ciudad de Talca en 1740. Fue teniente de milicias entre 1779-1782, participó en el Regimiento Húsares de la Frontera en 1782, capitán de milicias en Chillán y, finalmente, gracias a toda esta trayectoria, se le reconoció como caballero de la Real y Distinguida Orden de Carlos III 1797. Se radicó en el puerto de Cádiz para ejercer el comercio luego de una carrera como militar, lo que le permitió mantener una buena situación económica, no solo tuvo una estrecha amistad con Juan Ignacio Molina sino con importantes personajes protagonistas del proceso de independencia chileno como Bernardo O'Higgins siendo su apoderado en Europa. La amistad con Molina, lo llevó a traducir al español el Saggio sulla Storia Civile del Cile (1787) como Compendio sobre la Historia Civil del Reyno de Chile publicándola en imprentas hispanas en 1795.

34 Para una visión de conjunto sobre la respuesta de Molina, Velasco y Clavigero, véase Navia Méndez-Bonito, 2005. Bernard, 2009. Guasti, 2010. Chiaramonti, 2010. Brown, 1997. 
del nuevo mundo'35. Hasta ahí nada fuera de lo normal. Pero en el caso de Molina, dejar pasar rápidamente la palabra 'jardín' significa no considerar dos relevantes problemas históricos en la comprensión de la historia natural del exjesuita chileno en la cultura del illuminismo italiano de fines del settecento.

Expliquemos a que nos referimos con esto. Ha sido un acuerdo entre la gran cantidad de autores que componen la ingente bibliografía molineana, el interés y el conocimiento que el naturalista chileno tuvo de los autores y la cultura francesa. Una idea que puede ser refrendada cuando la Corte de Justicia Civil y Criminal de Bolonia, el 7 de julio de 1810, lo nombró intérprete oficial de francés dado su buen manejo de ese idioma ${ }^{36}$. Bajo este planteamiento, la historia natural del abate Molina descansaría en gran parte en los naturalistas, mineralogistas, químicos, geógrafos y viajeros franceses. Este favoritismo también se sostiene por la crítica que el exjesuita realizó al modelo taxonómico de Linneo a pesar de utilizarlo en su Saggio:

He seguido los pasos del naturalista Sueco, no porque esté yo persuadido de que su sistema sea superior á todos los otros, sino porque veo en el día es el mas generalmente seguido (...) no puedo dexar de decir que me desagrada en muchos puntos muy esenciales su ingeniosísima nomenclatura, y que con mayor gusto mio habría seguido (...) al gran Tournefort en la botánica ${ }^{37}$.

La predilección de Molina por el francés Joseph Pitton de Tournefort (16561708) frente al sueco Carlos Linneo (1707-1788) en la botánica y el francés Mathurin Jacques Brisson (1723-1806) en la zoología es porque autores como

35 Desde el siglo XVI, América ha sido objeto de interpretaciones y representaciones por parte de los europeos, a veces positivas, pero en su mayoría negativas como resultado del desconocimiento que tenían de su territorio y población. Hecho que se mantuvo a lo largo del período moderno. Se denomina «disputa del Nuevo Mundo» a las controversias culturales que se dieron entre europeos y americanos, particularmente en el siglo XVIII. La bibliografía sobre el asunto ha ido renovándose en los últimos años. No obstante, no puede dejar de señalarse la importancia de una obra fundamental como la de Gerbi, 1960. Este trabajo abrió el camino para que la actual historia cultural del conocimiento y la historia atlántica haya desarrollado investigaciones que han contribuido a la renovación del conocimiento sobre este asunto. Puede verse, por ejemplo, Cañizares Esguerra, 2007: 35-114 y 358-446. Bernard, 2009. Mestre Sanchis, 2003: 47-70. Así como para el siglo XVIII, el libro de referencia es el de Gerbi, para el siglo XVI nos parece de justicia hacer referencia a los insustituibles textos de Subirats, 1994 y Todorov, 1997. Más recientemente, para comprender las representaciones hechas sobre América en el siglo XVI y XVII, están, por ejemplo, los trabajos de Sanfuentes, 2009 y Rojas Mix, 2015.

36 Epistolario de Molina en Ronan y Hanisch, 1979: 75.

37 Molina, 1788: XII. 
ellos le «parecen mas fáciles al entendimiento común» ${ }^{38}$. Es decir, es un interés por su lenguaje simple, no tanto por su nacionalidad. Interés en un lenguaje que prescindiera de cualquier tipo de fanfarronerías dado su propósito de transmitir los nuevos conocimientos a un público menos especializado. No olvidemos que Molina junto con ser naturalista, fue instructor de niños. Considerando este hecho, y estudiando con mayor detenimiento las fuentes primarias utilizadas por el abate chileno, también podemos encontrar autores como Nicolás Sason D'Abbeville en la geografía — de quien exjesuita seguirá usando la carta geográfica sobre el Reino de Chile diseñada por el geógrafo francés en el siglo XVII-, Claude Buffier, Alexander Brongniart, Antoine Parmentier y, especialmente, el abate Nöel-Antoine Pluche con su obra Spectacle de la nature, ou Entretiens sur les particularités de l'histoire naturelle qui ont paru les plus propres à rendre les jeunes gens curieux et à leur former l'esprit publicada en París en 1732. Por supuesto, a pesar de sus críticas al Nuevo Mundo, la presencia entre sus referencias del afamado e insustituible Georges Louis Leclerc, Conde de Buffon, entre otros varios que podríamos señalar.

Hasta ahí, también todo parece claro. Que en la segunda mitad del siglo XVIII las referencias de científicos franceses fuesen obligadas para cualquier naturalista, incluso viniendo de un lugar tan alejado en el globo como el Reino de Chile, es un hecho que históricamente difícilmente puede discutirse. En un escenario dónde el predominio de la cultura francesa se hacía sentir con mucha vitalidad en las distintas monarquías y cortes europeas no se cuestiona.

Pero el historiador debe ser mucho más exigente. La palabra jardín utilizada por Juan Ignacio Molina para 'presentar' el Reino de Chile a la Europa ilustrada, bajo nuestro planteamiento, descubre un problema sobre las tradiciones cientificas presentes en el naturalista chileno que aún se encuentran pobremente reconocidas y con un destino lastimosamente velado. Por tanto, en considerando estas condiciones históricas, salta rápidamente una pregunta ila utilización de esta analogía sobre el 'jardín', un recurso retórico, expresa sencillamente el gusto clásico del naturalista chileno tan propio de la tradición intelectual renacentista que cualquier jesuita podía manejar? Bajo la perspectiva que considera el manejo de la información y la objetividad como un factor dinámico dentro del desarrollo de la sociedad en el período moderno, y considerando lo que han propuesto autores como $\mathrm{Mi}$ chèle Fogel ${ }^{39}$, Lorrain Darston ${ }^{40}$, Arnd Brendecke ${ }^{41}$ y particularmente Peter

\footnotetext{
38 Ibidem.

39 Fogel, 1989.

40 Daston y Galison, 2010.

41 Brendecke, 2012.
} 
Figura 2. Nöe-Antoine Pluche, Spectacle de la Nature, París, Tomo I, 1754.

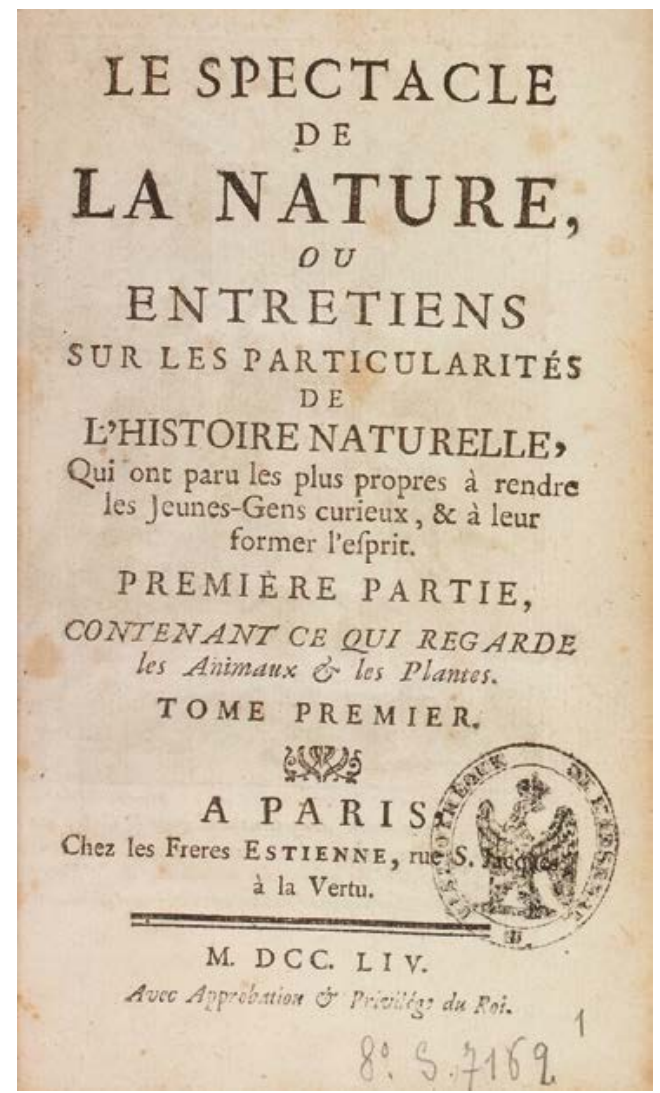

Fuente: Gallica. Bibliothèque nationale de France.

Burke ${ }^{42}$, por nombrar solo algunos que han tratado rigurosamente el problema de la naturaleza de la información junto a su circulación y transformación, nos parece que la historia natural en las últimas décadas del siglo XVIII no solo se vuelve un problema de información, sino también de tradición con complejas aristas que sobrepasan su naturaleza de saber científico.

42 El último libro del gran historiador cultural Peter Burke sobre la historia del conocimiento, quizás el historiador que más se ha preocupado por este complejo objeto de estudio, es una reflexión sintética, pero a la vez profunda, sobre los diversos tipos de conocimiento y los procesos históricos involucrados en su creación, usos y difusión. Véase Burke, 2017. 
UN SAGGIO PARA LA MONARQUía HISPANA DE FUENTES HISTÓRICAS INGLESAS E INFORMACIÓN GLOBAL

Para el estudio de la obra del naturalista chileno, se ha pasado por alto una cuestión fundamental para cualquier historiador: las fuentes históricas, es decir, la información utilizada por Molina para elaborar su relato. Sin duda, su estudio refleja las dificultades y las maneras de 'hacer ciencia' en las últimas décadas del siglo XVIII tras la crisis que vivió el antiguo modelo de historia natural desde la década de $1770^{43}$. Para comenzar un análisis de este tipo, si se me permite la comparación, la reconstrucción debe ser arqueológica, indicio por indicio, fragmento por fragmento, es decir, autor por autor. Esta reconstrucción arqueológica es una acción fundamental. Por tanto, se deben comprender y considerar qué fuentes primarias utilizó el abate chileno, la naturaleza de estas fuentes, por qué las seleccionó y, especialmente, cómo las utilizó en beneficio de sus intereses y preocupaciones como naturalista. Esto abrirá unas aristas de estudio hasta ahora impensadas porque el análisis se introduce en el complejo régimen intelectual que define la racionalidad de una obra científica. Simon Schaffer, estudiando una obra como los Principia Mathematica de Newton, ha denominado a este proceso de organización y negociación científica en un autor como el orden de la información ${ }^{44}$.

De tal forma, para realizar esta operación, hay que superar problemas que la propia historia ha puesto en el camino. Por ejemplo, Molina jamás viajó. Al menos de la manera que lo hicieron los 'viajeros ilustrados' en el siglo XVIII. Tanto en Chile, como en Italia, no realizó más que pequeñas y breves 'excursiones' a lugares cercanos: en Chile realizaba excursiones cerca de la hacienda de Huaraculén en la que creció y en los alrededores del Colegio de Bucalemu de la Compañía de Jesús en Chile ubicado aproximadamente a 175 kilómetros al sur de la ciudad de Rancagua. Ya en Europa, en Bolonia sus excursiones también fueron modestas en propósitos y distancias. La mayoría fueron a territorios que estaban fuera de las puertas de la ciudad, o a municipios cercanos como el de Porretta. Por último, realizó un viaje a Roma en 1789 por motivos que podríamos denominar como no científicos, pero dónde también aprovechó para realizar breves excursiones a las afueras de la ciudad eterna.

La pregunta puede sonar desdeñosa para algunos, pero es históricamente legítima: si Molina fue un naturalista ilustrado que no tuvo viajes con ambi-

43 Lepenies, 1991: 55-57.
44 Schaffer, 2009. 
ciosos propósitos científicos y de largas distancias que conectaran el globo, más allá del exilio jesuita que lo llevó de Chile al Puerto de Santa María en España en 1768 y luego el viaje que lo llevó a los Estados pontificios que fue realizado por las llamadas 'causas morales' ¿cómo pudo escribir el exjesuita la historia natural de 'todo' Chile si nunca lo recorrió en toda su extensión? Todo lo contrario ¿cómo pudo describir un territorio y sus producciones naturales tan desconocido tanto para los propios chilenos como para las otras partes del mundo? ¿Imaginación? Probablemente no de una forma categórica y en la forma que la entendemos y utilizamos actualmente - es decir, de una forma original que exprese algo diferente- , sino de una manera que lo original remita al estado inaugural y lo extraordinario de dicho estado inicial. Molina y su retórica objetivista, que solo utilizaba la 'conjetura' en ciertos momentos, parecía no estar del todo preparado para confiar completamente en un atributo como la imaginación. Pero sí había un arte que interesó al exjesuita desde pequeño como se vio en el apartado anterior: la literatura. Eso es un hecho.

Este pasatiempo de juventud en la figura del abate chileno - la literaturaquizás sin saber, se convirtió durante el proceso de formación como naturalista, de autoconstrucción de una identidad científica parafraseando al historiador Mario Biagioli, en un interesante recurso para Molina que le permitió 'viajar' y 'describir' el Reino de Chile como parte del 'resto del mundo'. Dicho de otra manera ¿cómo se explica que el naturalista chileno recurriera, como se aprecia con mucha claridad en la segunda edición de su Saggio sulla storia naturale de 1810, a obras que describían territorios tan distantes de Chile como, por ejemplo, la Relation historique de l'Ethiopie Occidentale contenant la Description des Royaumes de Congo, Angolle, \& Matamba del misionero capuchino italiano Giovanni Antonio Cavazzi (1621-1678) o la gran obra del botánico alemán Peter Simon Pallas (1741-1811) Voyages en differentes provinces de l'empire de Russie, et dans l'Asie septentrionale publicada entre 1788 y 1793 ?

De tal forma, la clave está en la 'arqueología de las fuentes' de Molina: su reconstrucción, autor por autor, arroja que gran parte de las fuentes utilizadas por el exjesuita para describir el territorio y las producciones naturales de Chile provino de la literatura de viajeros ilustrados. Y no de cualquier tradición: vino en gran parte de la tradición de viajeros y autores británicos. Sin duda, esto no quiere decir que el naturalista chileno no considerase a los viajeros franceses, y también a algún español. La reconstrucción de la arqueología de las fuentes primarias muestra que para él fueron relevantes seis viajeros franceses y dos españoles: Feuillée (1660-1732), Frezier (1682-1773), Bouganville (1729-1811), La Condamine (1701-1774) y Antonio de Ulloa 
Figura 3. Peter Simon Pallas, Voyages de M.S.Pallas

EN DIFFERENTES PROVINCES DE L'EMPIRE DE RUSSIE

et DANS L'Asie SEPTENTRIonale, PARIS, Tomo 15, 1793

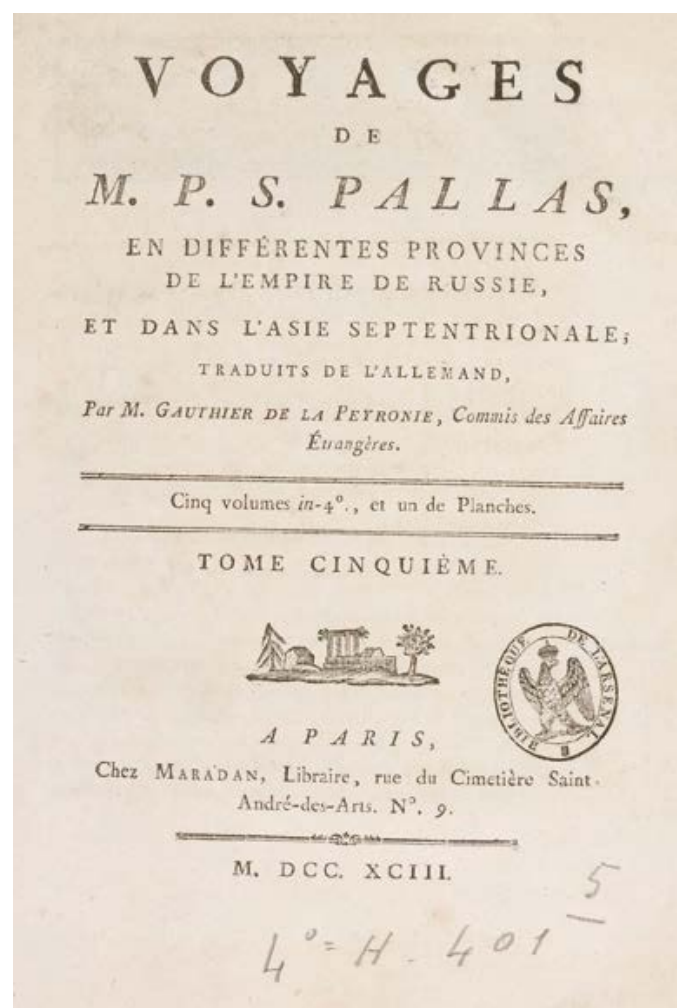

Fuente: Gallica. Bibliothèque nationale de France.

(1716-1795), Jorge Juan (1713-1773) y Joseph Dombey (1742-1794) ${ }^{45}$ que formaban parte de la misma expedición, y más tarde, la malograda expedición de circunnavegación del Conde de La Pérouse que desapareciese sin explicación en 1788 cerca de las aguas de las Islas Salomón.

Pero aquí va otro hecho: la importancia que la tradición intelectual británica ha tenido para Molina no se ha apreciado como es debido. No solo aparecen los grandes viajeros británicos del siglo XVIII como Lord Anson

45 Molina hace mucha diferencia entre las descripciones del francés Joseph Dombey y las hechas por el español Hipólito Ruiz quien estuvo a cargo de la Expedición botánica al Virreinato del Perú y Chile entre 1777 y 1788. 
(1697-1762), James Cook (1728-1779) y Joseph Banks (1743-1820) en la historia natural de Molina. También aparecen otros viajeros y autores de un segundo orden, pero no menos importantes, como John Woodward (16651728), Thomas Jefferys (1719-1771), John Hawkesworth (ca. 1713-1773), Daines Barrington (ca. 1727-1800), John Adams (1735-1826), el autor del Gazetero Americano, James Edward Smith (1759-1828), Samuel Wallis (17281795) y Philip Carteret (1733-1796), entre otros.

Dicha tradición, explica dos cosas importantes que se desprenden de la lectura de las obras de historia natural de Molina: a) su retórica objetivista y b) su sensibilidad literaria y apreciación estética de la naturaleza, especialmente con la introducción de un autor prerromántico, un hecho fundamental a nuestro juicio, como el poeta británico Lord Byron (1788-1824), nieto del viajero y navegante de la misma nacionalidad John Byron (1723-1786).

Explicaré estos puntos en que se refleja la presencia, y la relevancia, de las fuentes inglesas de viajeros y el propio escenario literario inglés para el naturalista chileno. La retórica objetivista desarrollada por Juan Ignacio Molina fue necesaria para escribir la historia natural de Chile. Escribirla suponía para el exjesuita resolver un problema científico importante para esa época: estabilizar y normalizar el precario y disperso conocimiento sobre la naturaleza de Chile. Para ello debía generar un relato creíble, en consecuencia, convertirse en un naturalista con credibilidad. Molina manifestó un profundo rechazo contra la utilización de silogismos y los sistemas filosóficos generales a los que consideraba artificiosos, pues, en su visión, no han sido resultado de la observación y de la experiencia ${ }^{46}$.

Este fue un planteamiento sustantivo en la 'filosofía natural' del abate chileno que ayuda a entender su apreciación de la naturaleza como obra estética. Según refleja su convicción filosófica, la naturaleza no era expresión de un modelo mecanicista y estático sujeto a leyes cerradas. Para Molina la naturaleza era una especie de laberinto lleno de 'escondrijos' que suele ocultar sus efectos más preciosos ${ }^{47}$. Casi idéntico planteamiento fue utilizado un siglo y medio antes por Francis Bacon (1561-1626) en su obra Novum Organum publicada en 1620 cuando observa: «Toda la industria del hombre estriba en aproximar las sustancias naturales unas a otras o en separarlas, el resto es una operación secreta de la naturaleza» ${ }^{48}$.

Para un autor preocupado por la teología natural como Bacon, la naturaleza actúa con sutileza, por lo que «las teorías por el hombre imaginadas, son

\footnotetext{
46 Molina, 1788: XVI.

47 Molina, 1810: 72.

48 Bacon, 1620: 33.
} 
peligrosas, a menos que se esté sobre aviso», pues de otra manera no podía penetrar en sus sombras. Cuando Molina, por ejemplo, describe el excesivo calor que se siente en la banda oriental de la Cordillera de los Andes, que no es diferente al que se experimenta en las regiones de África situadas bajo la misma latitud, la explica «porque la naturaleza se complace en traspasar las leyes que forman los hombres sin consultar y sin examinar los lugares á que las imponen ${ }^{49}$. La idea asumida por el exjesuita que la naturaleza se mueve por sus propias leyes, ya había sido expuesta por Bacon cuando escribe: «El espíritu humano se siente inclinado naturalmente a suponer en las cosas más orden y semejanza del que en ellas encuentra; y mientras que la naturaleza está llena de excepciones y de diferencias, el espíritu ve por doquier armonía, acuerdo y similitud» ${ }^{50}$.

Las coincidencias son muchas más y podríamos dar los suficientes ejemplos para comprobar esta arqueología intelectual. Lo claro es que se aprecia la adopción por parte de Molina, sin declararlo explícitamente como lo hace con otros autores importantes del siglo XVII ${ }^{51}$, de ciertos principios de la moderna filosofía natural de tradición inglesa. Por ejemplo, al describir el uso y la ubicación de algunas piedras calcáreas en el Reino de Chile, el exjesuita no duda en observar que «la naturaleza, en estos géneros, como en todos los otros, se complace en variar con alguna burla, sus producciones $\rangle^{52}$.

En estas palabras, el naturalista chileno reconoce un carácter arisco y montaraz en la propia naturaleza. La afirmación «se complace en variar con alguna burla», sugiere que la naturaleza, como expresión de Dios, se comporta súbitamente y tiene conductas inesperadas. A pesar de que la intención de la ciencia moderna es controlar y dominar, es decir, matematizar la naturaleza, esta, en la visión de Molina, va en contra de este tipo de acciones llevadas a cabo por el hombre. Y esta rebeldía de la naturaleza se expresará en una característica especial: la belleza de sus producciones que estarán dispuestas con perfección y libertad en el espacio.

Con este elemento, el naturalista chileno armoniza su ética ilustrada de la observación y la retórica objetivista con una preocupación moral muy propia

49 Molina, 1788: 28, 1810: 34.

50 Bacon, 1620: 42.

51 Por ejemplo, Atanasius Kircher, jesuita alemán a quien Molina nunca cita, pero cuyas metáforas y principios organicistas están presentes en los elementos que componen la reflexión de Molina sobre la estructura interna de la Tierra. Respecto a la figura y al extraordinario trabajo científico de Kircher, véase el buen trabajo de Paula Findlen, 2004. Sobre el aspecto particular de esta relación, y de la visión que el abate Molina desarrolló de la estructura interna de la Tierra, puede verse nuestro trabajo Orrego, 2015.

52 Molina, 1810: 73. 
de las inclinaciones románticas: la libertad. La crítica que realiza sobre el desconocimiento que los europeos tienen de Chile — sin duda refiriéndose a de Paw y compañía- la refuerza con una metáfora de representación dramática cuando en su Saggio sulla storia naturale de 1782 señala:

... todo el interior del país, que fue repartido con mas profusion de este genero de riquezas, permanece ignorado hasta nuestros días de los botanicos, los quales, si penetrasen mas adelante por aquel benefico clima, encontrarian un teatro enteramente nuevo de vegetacion ${ }^{53}$.

El entendimiento del Reino de Chile como un 'teatro' no representa un abuso de lenguaje, o un fetiche clasicista del exjesuita chileno. Refleja que él fue partidario de la idea que la naturaleza descansaba en espacios únicos, libres y originales. No discutiremos aquí los planteamientos políticos de Juan Ignacio Molina, pero lo que es relevante de esto es cómo utilizó recursos estéticos para su propósito científico-moral al que ya hicimos referencia antes: defender la dignidad y belleza de las producciones naturales del Reino de Chile.

\section{JARDINES INGLESES, DELEITE NATURAL Y PRERROMANTICISMO EN UN NATURALISTA DE LA AMÉRICA MERIDIONAL}

En una lectura por capas, el cumplimiento del propósito científico-moral exigía al abate Molina incorporar una retórica objetivista y empírica de figuras como Francis Bacon, sin obviar la autonomía de la naturaleza, pero también le exigía crear una retórica articulada en base a elementos éticos y estéticos que dieran paso a una morfología particular a la naturaleza. Con este propósito en mente, el paisaje y el clima inglés fueron de interés para el naturalista chileno que logró conocerlos a través de viajeros como John Byron, James Cook y Lord Anson. Estos autores le parecían necesarios no solo por la descripción que ellos hacían del territorio chileno, sino también por las comparaciones que realizaron con el territorio inglés. Bien sabida es la crítica que nuestro exjesuita hizo a los detractores del Nuevo Mundo sobre la hipotética presencia de un frío excesivo que cubría la América meridional. Para disputar este argumento, Molina recurre al relato del viaje del 'Comandante Byrón' en el HMS Doplhin en 1764 en el que señala,

Toda esta punta (Sandy) está cubierta de bosques, entre los cuales encontramos fuentes de agua dulce, y cuyos arboles y verduras presentan una vista agradabilí-

53 Molina, 1788: 126. La cursiva es nuestra. 
sima en casi dos leguas de tierra. Por encima de la punta se descubre un llano seguido, cuyo suelo parece fértil, y cuya tierra que llenaban el ayre de un delicioso perfume ${ }^{54}$.

Sobre la descripción hecha por Byron, que Molina recoge en su Saggio sulla sotira naturale, este se pregunta con mayor perspicacia:

¿más cómo es posible que se encuentre en medio de un frio excesivo una vegetación tan agradable y tan productiva? [...] Pues si el estio es tan rigido que se puede comparar según este autor con el corazón del invierno de Inglaterra ¿qué idea deberemos formar de los inviernos Magallanicos? ${ }^{55}$

«Agradable» y «reproductiva», en ese orden los términos, es lo relevante de su pregunta. A nuestro entender, la conjunción de estos calificativos y el uso de una fuente como la de John Byron, son claramente expresivos de la tensión entre el objetivismo de la cultura ilustrada y las inclinaciones a corrientes prerrománticas del abate chileno.

Es un acuerdo entre los historiadores que el movimiento prerromántico adquirió fuerza y visibilidad en Alemania en la década de 1770 con los intelectuales que formaron parte del llamado Sturm und Drang. Ahí estarían las raíces más sólidas e importantes. Sin embargo, para autores como Arnold Hauser (1962), el romanticismo tiene sus orígenes en Inglaterra. Allí, según Hauser, se produjo la síntesis del ideal burgués, el resorte social de las ya existentes corrientes prerrománticas. Para este autor, el ideal burgués, que está dominado por el individualismo y la pasión por la originalidad, se cuajó con mayor rapidez en Inglaterra que en otros países ${ }^{56}$. La mecanización del trabajo resultante de la revolución industrial, la objetivación creciente de la relación entre patrones y obreros, la concentración de trabajadores en las ciudades explicaría, en parte, la importancia del mundo inglés para las corrientes prerrománticas y el espiritualismo individualista. La crisis de ese «paisaje urbano», como resultado del avance de la revolución industrial, sin duda, hizo poner la atención de autores y viajeros ingleses en su opuesto: la naturaleza y el paisaje agreste. Y estos debían estar en un estado de libertad, sin intervenciones y límites que los restringieran.

Por lo anterior, la analogía del jardín adoptada por Juan Ignacio Molina al inicio de su Saggio de 1782 es reveladora de sus preferencias relativas a tradiciones científicas particulares. Para los ingleses, el jardín siempre ha sido

\footnotetext{
54 Molina, 1788: 19-20. La cursiva es nuestra.

55 Idem, p. 21.

56 Hauser, 1962, vol. II: 713-714.
} 
un espacio natural particular e importante en su vida cotidiana, lo que refleja una relación estrecha y original con la naturaleza. En 1772, el poeta inglés William Mason publicaba en Londres el primero de los tres volúmenes de su obra titulada The english garden: a poem, una de las obras literarias más importantes sobre el tema del jardín a fines del siglo XVIII. A mi entender, la obra no solo tiene un carácter literario, sino también científico. Y este carácter queda expresado por el propio autor cuando en la portada recurre, sin rodeos, a una definición de Francis Bacon:

A garden is the purest of human pleasures, it is the greatest refreshment to the spirit of man; without wich buildings and palaces are but gross handy-works. And a man shall ever see, that when ages grow to civility and elegancy, men come to build stately, sooner than to garden finely: as if gardening were the greater perfection ${ }^{57}$.

Recurriendo a la autoridad de Bacon, el poeta inglés reconoce el valor que tiene el jardín para la sociedad. De tal forma, podemos desprender de lo anterior, que el jardín es expresión del espíritu del hombre y de su civilidad. Tan interesado estuvo Juan Ignacio Molina en el paisaje y la tradición científica inglesa, encarnada en la idea de una naturaleza libre cuya descomunal belleza solo podía apreciarse realizando un ejercicio de contemplación y goce, que posterior a su ingreso a la Accademia delle Scienze de Bolonia en 1801, tras la intervención napoleónica en la ciudad, presentó en las adunanze de la academia una memoria titulada Los jardines ingleses que posteriormente fue publicada en $1821^{58}$. Molina, así como criticaba los sistemas filosóficos cerrados, también le irritaban profundamente las modas. Era un admirador de la tradición. Me he referido al interés que siempre se ha señalado por los autores franceses de parte del exjesuita chileno. También señalé que eso es así. Lo que no dije fue en qué términos se dio el interés de Molina por los autores franceses. Ahí está el punto de interés para un historiador.

Para Molina, los franceses podían llegar a ser muy desagradables porque aún eran «volubles en sus gustos y amigos de la novedad» ${ }^{59}$. Las conclusiones del abate chileno sobre la Francia del rococó son lapidarias en este sentido. Y su crítica a los franceses en este tema, que se expresaba en lo mundano de su gusto, tenía un nombre propio: «Lenotre y sus secuaces». Así se refería el naturalista chileno del creador de los magnánimos jardines de Luis XIV, el francés André Le Nôtre (1613-1700), y sus discípulos a pesar del crédito científico y social que poseía el 'jardinero y naturalista' del rey. Cuando se

\footnotetext{
57 Mason, 1783: portada s/p. La cursiva es nuestra.

58 Molina, 1821-1822.

59 Molina, 2003: 80.
} 
creó en Francia el jardín real en 1773, incluyendo en este proceso la participación del exiguo naturalista real Conde de Buffon, apoyado en la publicación de su Histoire naturalle, este hecho marca que los jardines en Francia, partiendo por el real, adquirieron de una forma u otra, la característica de ser sitios institucionalizados y abalados por el poder monárquico para la elaboración de conocimiento científico natural y entrega de información creíble como resultado de la creación de un 'programa histórico natural' con ejes específi$\cos ^{60}$. Es decir, pura expresión del poder de la razón ilustrada. Para el naturalista chileno, los jardines de Versalles, también parte de esos 'sitios naturales' que podemos denominar reales y que representan todo el gusto francés del período, no era más que un monótono e insípido diseño: «Los triángulos, los cuadrados, los rombos, los óvalos, las elipses, los pentágonos, los hexágonos, las líneas rectas y las paralelas se despliegan por doquier, figuras todas ellas que la naturaleza no utiliza jamás en sus pintorescos diseños» ${ }^{61}$.

La última aseveración es muy importante, pues como se ve, la crítica no solo tiene que ver con el diseño, sino con la filosofía natural que defendía: la autonomía y libertad de la naturaleza. En esto se puede ver la profundidad de la crítica de Molina a la tradición francesa. Alexandre Le Blond (1679-1719), talentoso alumno de Le Nôtre quien desarrollara un importante trabajo para Pedro el Grande (1672-1725), fue uno de los franceses que más cuestionó y criticó en este tema. El naturalista chileno conocía bien el Traité de la Théorie $d u$ Jardinage de Le Blond, a través de la lectura de un autor como Dezalliere D'Argenville y su obra La theorie et la pratique du jardinage publicado en París en 1709. El mayor desagrado que sentía Molina era la «amanerada distribución de los jardines» propuestos por Le Nôtre y Le Blond. El mayor pecado que cometían los arquitectos, artistas y naturalistas franceses era someter a la naturaleza a una suerte de coincidencia y equilibrio, es decir, la geometrización de la disposición de sus animadas producciones. El abate chileno entendía que «de la uniformidad nace el aburrimiento» ${ }^{62}$.

$\mathrm{Y}$ en el aburrimiento, por cierto, no hay gusto. El estilo de la historia natural del exjesuita chileno está dominado por flores, árboles, fuentes, ríos, delicias, prodigios, jardines, teatros, perfumes. Son estos los componentes de ese «jardín de la América» que permiten llevar una «vida cómoda y apacible». En ese «teatro fértil de vegetación» que era el Reino de Chile, tan desconocido para los europeos, estaba el origen de todo deleite para el hombre. Para el exjesuita chileno, en la Naturaleza, que no responde a leyes, está el origen

\footnotetext{
60 Cfr. Spary, 2000: 17 y ss.

61 Molina, 2003: 81. La cursiva es nuestra.

62 Idem.
} 
de toda complacencia y regocijo individual. Allí radica la dura crítica a los autores y jardines franceses:

En efecto, la naturaleza, verdadera fuente de todo deleite razonable, está allí del todo y por todo forzada y contrariada. La primera visión [de tales jardines] verdaderamente os sorprende; a la segunda, la mente permanece tranquila; a la tercera, cesa la ilusión, se descubre el arte y la fascinación se desvanece del todo. La experiencia nos muestra la realidad de este efecto ${ }^{63}$.

En esta cita, se ve que el exjesuita chileno pasa de la observación de la naturaleza a una suerte de apreciación moral de ella, es decir, al goce y al disfrute de ella. Dado que los jardines son una re-creación de la naturaleza, Molina cuestiona los jardines franceses de estilo matemático porque le parecen un latoso artificio. Para él, el peligro estaba en la monotonía, pues la monotonía, en cierto sentido, representaba la muerte de la naturaleza. La obra de Dios solo representa vida. De acuerdo con su reflexión histórica, la naturaleza misma es un espectáculo y el «espectáculo es ilusión». Incluso Molina va más allá cuando señala que en los jardines ingleses se encuentra «una admirable simplicidad, una variedad encantadora, un bello desorden, escenas siempre nuevas, en fin, la naturaleza que han desterrado de sus moradas» ${ }^{64}$.

Por tanto, la libertad de la naturaleza, una razón moral, se expresa en un «bello desorden». En la aparente desorganización de los jardines de tradición inglesa, frente a la rígida geometrización francesa, Molina encontró un argumento de originalidad y belleza para poder dotar el territorio de Chile de buenas características. Por este motivo, celebró la introducción de los jardines ingleses en Francia realizada por el dramaturgo parisino Charles Dufresny (1657-1724), quien diseñara los jardines cerca de los poblados de Poissy y Vincennes, ubicados en los alrededores de París. El naturalista chileno conocía muy bien, como se desprende de la lectura de su memoria sobre los jardines, la obra de poetas románticos ingleses como Milton, Thomson y Addison.

Bastaría con introducirnos en las polémicas de los poetas franceses de la segunda mitad del siglo XVIII, para comprender el impacto que generó la introducción de la tradición inglesa sobre los jardines en Francia. Por ejemplo, el abate chileno valoró positivamente los trabajos del francés Claude Henri Watelet (1718-1786), hombre de múltiples intereses, y su obra Essai sur les jardins publicado en 1774 o el trabajo del alemán Christian Lorenz Hisschfeld (1742-1792) titulado Theorie der Gartenkunst publicado en 1775. Ambas obras se basaron fuertemente en los principios ingleses desarrollados sobre los jardines. La intro-

\footnotetext{
63 Idem. 81. La cursiva es nuestra.

64 Idem. La cursiva es nuestra.
} 
ducción del modelo inglés de jardín en Francia por autores como Watelet representó de cierta forma para el naturalista chileno el ingreso del buen gusto.

Aunque esto sea algo que debe estudiarse con más profundidad de lo que permite esta ponencia, pareciera ser que cuando se publica el Saggio sulla storia naturale del Chili en 1782, mismo año en el que ve la luz el poema del abate Jacques Delille (1738-1813) titulado Les jardins que tanto gustó a Molina, el exjesuita ya tenía un claro interés por la tradición científica y literaria inglesa. Una interesante relación entre ciencia y arte, encarnado en la expresión literaria, que en último término podría tener su origen en el conocimiento que el abate chileno tuvo de la tradición de viajeros y autores ingleses. La relación con la literatura, como expresión de su formación clásica, puede ser que explique, en parte, que criticara a grandes exponentes de la ciencia ilustrada. Ejemplo de ello fue el reconocimiento que hizo en su memoria sobre los jardines al naturalista suizo, pero también poeta, Albrecht von Haller (1708-1777). Von Haller fue un gran adversario de Linneo, del que como dijimos, y a pesar de la trascendencia del botánico sueco, Molina nunca fue un gran admirador. Como ilustrado que fue, el exjesuita chileno fue exigente intelectualmente, y parece le cautivaron autores que no fueran simples científicos, debían dar algo más.

Y esto, a juicio nuestro, tiene una explicación que se debe atender: Molina además de naturalista, fue historiador. Pareciera una obviedad, pero subestimar las obviedades resulta demasiado peligroso para los historiadores. Este planteamiento refleja la relevancia que el abate Molina dio a la tradición, es decir, a 'lo antiguo', 'lo memorable'65. Sin duda, cuando llegó a Italia debió haberse dado cuenta de la relevancia histórica que posee un espacio como el jardín para el hombre. Los jardines que habían cultivado los antiguos romanos eran, para el exjesuita chileno, expresión de su desarrollo como civilización. Cuando las tribus bárbaras arrasaron los territorios romanos, no solo destruyeron un orden civil sino también corrompieron el gusto. Por ello, para el naturalista chileno, el jardín es un 'recreación' y una práctica del 'hombre civilizado'66.

Ya para ir concluyendo, llegamos a un punto interesante dónde surge un cuestionamiento que parece está en condiciones de realizarse sin aprensiones. Al utilizar la metáfora de 'Jardín de la América' ¿Molina no intentaba poner al Reino de Chile en un sitio importante dentro de la historia occidental? ¿El deleite de la naturaleza, además de tener una dimensión estética, no posee una connotación histórico-moral también? En su historia natural de Chile defiende el siguiente argumento, sin duda, en respuesta directa a Cornelius de Paw:

65 Molina, 1788: 12-13.

66 Molina, 2003: 80. 
El Reyno de Chile es uno de los mejores países de toda la América; pues la belleza de su cielo, y la constante benignidad de su clima, que parece que se han puesto de acuerdo con la fecundidad y riqueza de su terreno, le hacen una mansión tan agradable, que no tiene que envidiar ningun dote natural de quantos poseen las mas felices regiones de nuestro globo ${ }^{67}$.

Pero más allá de la respuesta a los detractores de la naturaleza del Nuevo Mundo, el anterior argumento revela mucho más: la conjunción que realiza el exjesuita chileno entre su apreciación estética de la naturaleza con una 'conciencia global'. Como hemos dicho, Molina no 'circunnavegó', pero encontró otras formas de 'viajar' por el globo, un término muy utilizado por los grandes viajeros dieciochescos. Viajes literarios si se quiere son los realizados por nuestro naturalista. A través de la incorporación de los viajeros y autores ingleses logró conocer la amplitud que tenía 'el globo'.

\section{CONCLUSIONES}

Hablar de naturaleza, de bellos ríos, hermosos árboles, cristalinas fuentes, en la historia natural de Molina es hablar de deleite. Y el deleite, en su historia natural, es esencialmente hablar de un problema literario, de expresividad retórica, de sensibilidad y agudeza en la observación de la naturaleza. En consecuencia, hablar de deleite es hablar de crítica a los modelos explicativos de ella - la naturaleza - que descansaron en una excesiva matematización. El interés por las fuentes de información y los jardines ingleses son el reflejo del tránsito, casi inevitable, de un saggiatore ilustrado a un naturalista prerromántico.

Este artículo ha sido un arranque: no solo representa el estudio de la historia natural de Chile, sino también un intento por comprender los avatares y la racionalidad de algunas tradiciones científicas en el complejo paso cultural y político del siglo XVIII e inicios del XIX en la Italia de fin de siglo. El interés del naturalista chileno por el jardín, como metáfora estético-literaria y como espacio natural como parte de una pedagogía moral y confesional, no evidencia solamente la atracción que sintió por la ciencia inglesa y sus viajeros. También muestra la importancia que el exjesuita chileno dio a la convivencia estrecha e íntima que el hombre debía establecer con la naturaleza. Allí radica el deleite de ella. En esa convivencia, el jardín que recrea la naturaleza se convierte en un espacio privilegiado para la expresión del espíritu. Un

67 Molina, 1788: 15. 
acto de subjetivismo prerromántico. Pero el interés en el jardín, ya no como analogía o fórmula retórica, también está en la posibilidad que este espacio daba a los naturalistas que, como Molina, no pudieron realizar grandes viajes. En el jardín se podían plantar especies y «ver qué pasaba» con ellas. El jardín fue un espacio que, al menos en parte, permitió a Molina observar, describir, reflexionar y ensayar ideas y hechos sobre la naturaleza, pero también le posibilitó su contemplación y deleitarse con ella.

\section{BIBLIOGRAFÍA}

Bacon, Francis, Novum Organum, Madrid, Alianza, 1985 [1620].

Batllori, Miguel, La cultura hispano-italiana de los jesuitas expulsos. Españoles, hispanoamericanos y filipinos (1767-1814), Madrid, Biblioteca Románica Hispánica, Editorial Gredos, S.A., 1966.

Bernard, Carmen, "La marginación de Hispanoamérica por la Historia universal europea", Revista Co-herencia, 6/11 (Medellín, 2009): 107-122.

Beruete, Santiago, Jardinosofía. Una historia filosófica de los jardines, Madrid, Turner Publicaciones S. L., 2016.

Brañes, María José, "Letras latinas en Chile colonial", Stefanie Massmann (coord.), Historia crítica de la Literatura Chilena, Vol. I, Santiago, LOM Ediciones, 2017: 395-408.

Brendecke, Arndt, Imperio e información. Funciones del saber en el dominio colonial español, Madrid, Iberoamericana-Vervuert, 2012.

Briones, Hernán, El abate Juan Ignacio Molina. Ensayo crítico-introductorio a su vida y su obra, Santiago, Editorial Andrés Bello, 1968.

Brown, Stewart J. (ed.), William Robertson and the expansion of empire, Cambridge, Cambridge University Press, 1997.

Burke, Peter, ¿Qué es la historia del conocimiento? Cómo la información dispersa se ha convertido en saber consolidado a lo largo de la historia, Buenos Aires, Siglo XXI Editores, 2017.

Cañizares Esguerra, Jorge, Cómo escribir la historia del Nuevo Mundo. Historiografías, epistemologías e identidades en el mundo del Atlántico del siglo XVIII, México, Fondo de Cultura Económica, 2007.

Chiaramonti, Gabriella, "Le 'Storie' americane dei gesuiti espulsi: Juan Ignacio Molina tra amore per la verità e passione per la patria cilena", Ugo Baldini y Gian Paolo Brizzi (eds.), La presenza inItalia dei gesuiti iberici espulsi. Aspetti religiosi, poliitici, culturali, Bolonia, CLUEB, 2010: 465-494. 
Contreras, Manuel, "La 'Conquista Espiritual del Reino de Chile', de Diego de Rosales, como fuente para el estudio de la morfosintaxis del español de Chile colonial", Onomazéin. Revista de lingüística, filología y traducción, 37/4 (Santiago, 2017): 41-59, https://doi.org/10.7764/onomazein.37.07

Daston, Lorraine y Galison, Peter, Objetivity, Nueva York, Zone Books, 2010.

Espinosa, Januario, El abate Molina. Uno de los precursores de Darwin, Santiago, Editorial Zig-Zag, 1946.

Ette, Ottmar, Literatura en movimiento. Espacio y dinámica de una escritura transgresora de fronteras en Europa y América, Madrid, CSIC, 2008.

Findlen, Paula (ed.), The Last Man Who Knew Everything, Nueva York y Londres, Routledge, 2004.

Fogel, Michèle, Les cérémonies de l'information dans la France du XVIe au XVIIIe siècle, París, Fayard, 1989.

Francis, Mark, Herbert Spencer and the invention of modern life, Londres, Acumen Publisher, 2008.

Gaune, Rafael, "Diego de Rosales: jesuita, escritor, anticuario", Stefanie Massmann (coord.), Historia crítica de la Literatura Chilena, Vol. I, Santiago, LOM Ediciones, 2017: 213-228.

Gerbi, Antonello, La disputa del Nuevo Mundo. Historia de una polémica, 17501900, México, Fondo de Cultura Económica, 1960.

Guasti, Niccolò, "Rasgos del exilio italiano de los jesuitas españoles", Hispania Sacra, LXI/123 (Madrid, 2009): 257-278. https://doi.org/10.3989/hs.2009.v61.i123.87

Guasti, Niccolò, "Il tema americano nelle strategie culturali dei gesuiti spagnoli espulsi", Ugo Baldini y Gian Paolo Brizzi (eds.), La presenza inItalia dei gesuiti iberici espulsi. Aspetti religiosi, poliitici, culturali, Bolonia, CLUEB, 2010: 411-450.

Hachim Lara, Luis, "El jesuita Juan Ignacio Molina y el pensamiento crítico", Stefanie Massmann (coord.), Historia crítica de la Literatura Chilena, Vol. I, Santiago, LOM Ediciones, 2017: 325-335.

Hanisch, Walter, Un ataque dieciochesco a Juan Ignacio Molina, Santiago, Nihil Mihi, 1976.

Hanisch, Walter, Juan Ignacio Molina y sus Obras, Talca, Editorial Universidad de Talca, 1999.

Hauser, Arnold, Historia social de la literatura y el arte, Madrid, Ediciones Guadarrama, 1962.

Jaramillo Barriga, Rodolfo, "El abate Juan Ignacio Molina, primer evolucionista y precursor de Teihard de Chardin", Mapocho, 3/2/8 (Santiago, 1965): 37-53. 
Lepenies, Wolf, La fine della storia natural. La trasformazione di forme di cultura nelle scienze del XVIII e XIX secolo, Bologna, Il Mulino, 1991.

Locke, David, La ciencia como escritura, Madrid, Cátedra, 1997.

Mason, William, The English Garden, York, A. Ward, 1783.

Mestre Sanchis, Antonio, Apología crítica de España en el siglo XVIII, Madrid, Marcial Pons Historia, 2003.

Millones Figueroa, Luis y Ledezma, Domingo (eds.), El saber de los jesuitas, historias naturales y el Nuevo Mundo, Madrid-Frankfurt, Iberoamericana-Vervuert, 2005.

Molina, Juan Ignacio, Memorie di Storia Naturale, Bologna, Tipografia Marsigli, 1821-1822.

Molina, Juan Ignacio, "Memoria VII. Los jardines ingleses", Patricio Oyaneder Jara, Saber y saborear. Cuatro "Memorias del Abate Molina, Concepción, Editorial Universidad de Concepción, 2003: 73-100.

Molina, Juan Ignacio, Compendio de la historia geográfica, natural y civil del Reyno de Chile, escrito en italiano por el abate Don Juan Ignacio Molina, traducida en español por Domingo Joseph de Arquellada Mendoza y por Don Nicolás de la Cruz y Bahamonde, 1788 [Edición facsimilar, Santiago, Biblioteca del Bicentenario, Pehuén Editores Ltda., 2000, tomo I].

Molina, Juan Ignacio, Elegias latinas de la viruela, Santiago, Nihil Mihi, 1976 [1761].

Molina, Juan Ignacio, Ensayo de Historia Natural,Talca, Ediciones Universidad de Talca, 1987 [1810].

Mollano, Hugo I., "En el tercer centenario del nacimiento de Carlos Lineo: Lineo y Molina develadores de la biodiversidad chilena", Gayana, 72/2 (Concepción, 2008): 127-130. https://doi.org/10.4067/s0717-65382008000200002

Navia Méndez-Bonito, Silvia, "Las historias naturales de Francisco Javier Clavijero, Juan Ignacio Molina y Juan de Velasco", Luis Millones Figueroa y Domingo Ledezma (eds.), El saber de los jesuitas, historias naturales y el nuevo mundo, Madrid-Frankfurt: Iberoamericana-Vervuert, 2005: 225-250.

Nieto Olarte, Mauricio, Las máquinas del imperio y el reino de Dios. Reflexiones sobre ciencia, tecnología y religión en el mundo atlántico del siglo XVI, Bogotá, Universidad de los Andes, 2013.

Orrego González, Francisco, "Juan Ignacio Molina y la comprensión de la naturaleza del Finis Terrae. Un acercamiento desde la historia (cultural) de la ciencia", Arbor. Ciencia, Pensamiento y Cultura, 187/751 (Madrid, 2011): 961-976. https:// doi.org/10.3989/arbor.2011.751n5012

Orrego González, Francisco, “El 'mundus subterraneus' de Juan Ignacio Molina o el geólogo como economista", Asclepio. Revista de Historia de la Medicina y de la Ciencia, 67/2 (Madrid, 2015), p112. https://doi.org/10.3989/asclepio.2015.30 
Orrego González, Francisco, "Juan Ignacio Molina y la información global. Un Sagiattore del 'Finis Terrae' (1782-1810)", Vencer la distancia, 23/12/2017. http:// distancia.hypotheses.org/1035

Orrego González, Francisco, 'El huevo o el fango. Juan Ignacio Molina ¿'Precursor' del evolucionismo moderno?", Gustavo Vallejo, Marisa Miranda, Rosaura Ruiz Gutiérrez y Miguel Á. Puig-Samper (eds.), Darwin y el darwinismo desde el sur del sur, Aranjuez, Ediciones Doce Calles, CONICET, Universidad Nacional de Quilmes, UNAM, 2018: 75-98.

Pimentel, Juan, Testigos del mundo. Ciencia, literatura y viajes en la Ilustración, Madrid, Marcial Pons Historia, 2003.

Rojas Mix, Miguel, El fin del Milenio y el sentido de la historia. Manuel Lacunza y Juan Ignacio Molina, Santiago, LOM Ediciones, 2001.

Rojas Mix, Miguel, América Imaginaria, Santiago, Erdosain Ediciones, Pehuén Editores, 2015.

Ronan, Charles E. y Hanisch, Walter, Epistolario de Juan Ignacio Molina, Santiago, Editorial Universitaria, 1979.

Safier, Neil, La medición del Nuevo Mundo. La ciencia de la Ilustración y América del Sur, Madrid, Fundación Jorge Juan, Marcial Pons Historia, 2016.

Saldivia, Zenobio, “Juan Ignacio Molina, primer científico chileno”, Humanidades em foco. Revista de Ciencia, Educaçao e Cultura, 2 (Valparaíso de Goiás, 2004). http://terra.cefetgo.br/cienciashumanas/humanidades_foco/anteriores/humanidades_2/textos/molina.pdf

Salinas, Augusto, "El abate Molina y la ciencia de su época”, Universum, 13 (Talca, 1998): 211-226.

Sanfuentes, Olaya, Develando el Nuevo Mundo. Imágenes de un proceso, Santiago, Ediciones Universidad Católica de Chile, 2009.

Schaffer, Simon, "Newton on the Beach: The information order of Principia Mathematica", History of Science, 47, (Cambridge, 2009): 243-276. https://doi. org/10.1177/007327530904700301

Shapin, Steven, La revolución científica. Una interpretación alternativa, Barcelona, Ediciones Paidós Ibérica, S.A., 2000.

Spary, Emma C., Utopia's Garden. French Natural History from Old Regime to Revolution, Chicago y Londres, The University of Chicago Press, 2000.

Spencer, Herbert, "Progress: its Law and Cause", The Westminster Review, 67 (Londres, 1857): 445-485.

Subirats, Eduardo, El continente vacio. La conquista del Nuevo Mundo y la conciencia moderna, México, Siglo XXI editores, 1994. 
Todorov, Tzvetan, La Conquista de América. El problema del otro, México, Siglo XXI Editores, 1997.

Valverde, Nuria, Un mundo en equilibrio. Jorge Juan (1713-1773), Madrid, Fundación Jorge Juan, Marcial Pons Historia, 2012.

Fecha de recepción: 17 de enero de 2018.

Fecha de envío de las modificaciones: 6 de marzo de 2018.

Fecha de aceptación: 21 de marzo de 2018.

\section{"The garden of South America..." Science as delight, information and the charm of English gardens as described by a Chilean naturalist in the Italian Enlightenment}

This article seeks to explore one of South America's diverse cultural representations produced by one of the many expelled Jesuits who settled in Settecento Italy: Chilean naturalist and historian Juan Ignacio Molina (1740-1829). The metaphorical expression "the Garden of America" plunges us into the cultural controversies surrounding a historical object - the special kind of natural scenery constituted by a garden - that has been studied little by cultural historians. By studying Molina's natural history of Chile and a report on English gardens he defended in Bologna's Academy of Sciences in the early nineteenth century, it can be maintained that, in view of the information sources on which he drew in these works, in the specific cultural setting of Italian Illuminismo, the Chilean naturalist can be considered a pre-Romantic author.

KEY WORDS: Juan Ignacio Molina; natural history; gardens; sources of information; pre-romanticism. 